\title{
Looking at Life from Different Angles: Observer Perspective during Remembering and Imagining Distinct Emotional Events
}

\author{
Hildur Finnbogadóttir and Dorthe Berntsen
}

Center on Autobiographical Memory Research, Department of Psychology and Behavioural Sciences, Aarhus University, Bartholins Allé 9, Building 1340, 8000 Aarhus C, Denmark.

NOTICE: this is the author's version of a work that was accepted for publication in Psychology of Consciousness: Theory, Research, and Practice. Changes resulting from the publishing process, such as peer review, editing, corrections, structural formatting, and other quality control mechanisms may not be reflected in this document. Changes may have been made to this work since it was submitted for publication. A definitive version was subsequently published in Psychology of Consciousness: Theory, Research, and Practice, 1, 387-406.

This article may not exactly replicate the final version published in the APA journal. It is not the copy of record.

Link to the article: http//dx.doi.org/10.1037/cns0000029

(C) 2014 APA 


\begin{abstract}
We examined the use of observer perspective-i.e., seeing oneself from an observer's perspective when remembering and imagining personal events — in relation to worry and other types of maladaptive thinking styles. We examined this relation across a range of discrete emotions. In Study 1, we found that high worriers compared with low worriers use more observer perspective when remembering and imagining emotional (fear, joy, shame, pride), important, and word-cued events. Across emotional and word-cued events, and for both past and future temporal direction, high worriers reported more observer perspective than low worriers. In Study 2, we examined the use of visual perspective in relation to worry and other measures of negative affect and thinking styles, when remembering events involving positive versus negative evaluation of self versus others (shame, pride, contempt, admiration). We found that measures of general anxiety, symptoms of social anxiety, and rumination were associated with greater observer perspective, whereas reflection was associated with more field perspective. Together, the two studies show that high levels of maladaptive thinking and negative affect are associated with using more observer perspective when imagining and remembering autobiographical events across a range of emotions.
\end{abstract}




\section{Looking at Life from Different Angles: Observer Perspective during}

\section{Remembering and Imagining Distinct Emotional Events}

When remembering (or imagining) personal events you may either see what happens as through your own eyes (i.e., in field perspective), or you may see the event from the outside as an observer might see it (i.e., in observer perspective; Nigro \& Neisser, 1983). The perspective one adopts during retrieval usually occurs automatically (although it can also be controlled at will), and perspective is not necessarily stable during recall of the same memory, but may change as the remembered event unfolds (Berntsen \& Rubin, 2006b; Rice \& Rubin, 2009).

Research has shown that field perspective is more common than observer perspective, with only a minority of memories recalled from observer perspective (Nigro \& Neisser, 1983; but see Rice \& Rubin, 2011). However, when imagining possible future events, observer perspective is slightly more common (e.g., Berntsen \& Bohn, 2010; Berntsen \& Jacobsen, 2008; Finnbogadottir \& Berntsen, 2011). Here, we examine the use of observer perspective in relation to worry and related types of maladaptive thinking when imagining and remembering autobiographical events associated with different types of emotion.

\section{Observer Perspective in Healthy Adults}

Researchers have found that the use of observer perspective during recall is related to a number of factors (see Rice, 2010, for an extensive review). Recalling a memory from an observer perspective, compared with a field perspective, for instance, tends to involve older events (e.g., Nigro \& Neisser, 1983; Piolino, Desgranges, Clarys, Guillery-Girard, Taconnat et al., 2006; Robinson \& Swanson, 1993). This finding may be mediated by the decrease in vividness of the memories that occurs with increased age of the memories (Talarico \& Rubin, 2003). Indeed, visual 
vividness seems to be an important factor. For example, a study by Rubin, Burt and Fifield (2003) found that participants who had no visual information at encoding were more likely to retrieve the encoded event from observer perspective compared with participants who had access to visual information at encoding.

Use of observer perspective is also related to self-awareness, in that emotions selected to be high on intensity and self-awareness engender more observer memories than high intensity emotions low on self-awareness (Nigro \& Neisser, 1983). Furthermore, individuals who score high on public self-consciousness are more likely to remember from an observer perspective (Robinson \& Swanson, 1993). Finally, instructions to use observer perspective during retrieval results in more thoughts about being evaluated by others and more intense self-conscious emotions, but less thoughts about situational circumstances and less intense hedonic emotions (e.g., joy, sorrow) than instructions to use field perspective (Hung \& Mukhopadhyay, 2012).

However, researchers have determined that, in general, retrieving memories from an observer perspective involves less emotional reliving during recall (e.g., Berntsen \& Rubin, 2006b; Crawley \& French, 2005; Mclsaac \& Eich, 2002; D'Argembeau, Comblain, \& Van der Linden, 2003; Nigro \& Neisser, 1983; Talarico, LaBar, \& Rubin, 2004). For instance, instructing individuals to focus on emotional details during retrieval produces more field memories and fewer observer memories than instructing individuals to focus on the objective circumstances of events (Nigro \& Neisser, 1983). Moreover, instructing individuals to change from field to observer perspective leads to a decrease in experiential ratings, whereas the converse shift from observer to field perspective does not result in an increase in such ratings (Berntsen \& Rubin, 2006b; Robinson \& Swanson, 1993; Williams \& Moulds, 2008). Regarding effects on mood, one study found that using field perspective increased positive mood when imagining positive events, whereas observer perspective leads to reductions in positive mood (Holmes, Coughtrey, \& Connor, 2008). Finally, 
field perspective produces greater emotionality and feelings of nervousness, compared with observer perspective when recalling negative, non-traumatic events (Terry \& Horton, 2007-2008). Thus, observer perspective seems to be associated with reduced emotional intensity of the events recalled (and perhaps imagined), as well as less mood impact, although the dampening effect of observer perspective may also depend on the type of emotion and event under study (e.g., Hung \& Mukhopadhyay, 2012).

Research on healthy participants suggests that observer perspective accentuates perceived change, so that observer perspective is more likely to be adopted when thinking about how one has changed since some past event, compared with when thinking about similarities between the current and past self (Libby, Eibach, \& Gilovich, 2005). Observer perspective is also more likely to be adopted when thinking about the broader meaning of events (Libby \& Eibach, 2011). Furthermore, researchers have found that visual perspective affects attribution, in that observer perspective is associated with making more dispositional attributions for behavior when recalling past events (e.g., Frank \& Gilovich, 1989), possibly because visual perspective influences what information is attended to (Hung \& Mukhopadhyay, 2012). Finally, imagined future events are generally associated with higher levels of observer perspective than remembered past events (e.g., Finnbogadottir \& Berntsen, 2011).

\section{Observer Perspective in Relation to Emotional Distress}

Reported use of observer perspective is elevated in various populations suffering from anxiety (Terry \& Horton, 2007-2008), including PTSD (e.g., McIsaak \& Eich, 2004) and social phobia (e.g., Wells, Clark, \& Ahmad, 1998), as well as in depression and dysphoria (e.g., Williams \& Moulds, 2007). Many hypotheses have been put forward to explain the function of observer perspective in the context of psychological distress, and these hypotheses differ regarding whether 
observer perspective serves adaptive or maladaptive functions. In the context of PTSD and depression, researchers have suggested that observer perspective may function as avoidance, reducing emotional intensity in the short-term, but maintaining psychological distress in the longterm (e.g., McIsaak \& Eich, 2004; Williams \& Moulds, 2007, 2008). In contrast, cognitive models of social phobia suggest that observer perspective is due to increased self-focused processing, which heightens anxiety (e.g., Clark \& Wells, 1995). In the context of depression, Holmes et al. (2008) have suggested that observer perspective contributes to the lack of a "rose-tinted" view of the future, characteristic of healthy individuals, by inhibiting enhancement of positive mood when imagining positive events (Holmes et al., 2008). With respect to anger, adopting observer perspective while thinking analytically about an anger-evoking event may serve as an adaptive emotion regulation strategy and thereby reduce anger (e.g., Kross, Ayduk, \& Michel, 2005). Furthermore, the distancing function provided by observer perspective may be beneficial when the event remembered is a negative one (Wilson \& Ross, 2003). Finally, in the context of PTSD, observer perspective may be adaptive in relation to recalling negative events, as it highlights the discrepancy between the remembered self and the current self (i.e., accentuates change cf. Libby et al., 2005), thereby preventing the negative event from becoming central to identity (Robinaugh \& McNally, 2010). Based on the literature to date, it is not clear when or how observer perspective can be considered maladaptive. The reason for these differing views and findings may be that they stem from different (a) fields of study; (b) populations, problems, and disorders sampled; (c) events under study; and (d) experimental methodologies (Rice, 2010; Terry \& Horton, 2007-2008). 


\section{Observer Perspective in Relation to Worry and Other Forms of Maladaptive Repetitive}

\section{Thinking}

Use of observer perspective has been found to be associated with the tendency to ruminate and it has been suggested that this link between rumination and observer perspective may be due to avoidance of affect (Williams \& Moulds, 2007, but see also Williams \& Moulds, 2008). Indeed, explanations that center on avoidance or distancing have been offered in accounts of greater use of observer perspective in the context of depression and anxiety disorders. Rumination may be defined as repetitive negative thinking about the past (Thomsen, 2006), whereas worry is focused on future, negative events (Barlow, 2002). Worry and rumination tend to co-occur in the same individual, and may share the same processes but involve different content, in that they belong to the broader category of maladaptive repetitive thinking, characterized by abstract, evaluative thinking about the meaning, causes, and consequences of events (Watkins, 2008, p. 188). Worry and rumination show similar proportions of verbal thought versus imagery (for review see Watkins, Moulds \& Mackintosh, 2005), and the verbal, abstract nature of worry and rumination may function as avoidance (e.g., Borkovec, Alcaine, \& Behar, 2004; Cribb, Moulds \& Carter, 2006): Individuals with a high tendency to worry and to ruminate exhibit a general tendency to avoid emotional experiencing (e.g., Cribb et al., 2006; Giorgiou, Sanflippo, Kleiman, Reilly, Bender et al., 2010; Roemer, Salters, Raffa, \& Orsillo, 2005; Salters-Pedneault, Tull, \& Roemer, 2004). In light of these findings, we previously hypothesized that the tendency to worry would be associated with greater use of observer perspective, although our research did not support this hypothesis when we examined word-cued and spontaneously arising memories and images of future events (Finnbogadottir \& Berntsen, 2011). The principal aim of the current Study 1 was to examine this hypothesis further across a range of emotional and word-cued events. 
Researchers have suggested that maladaptive repetitive thinking, such as rumination, is a type of self-focus motivated by fear, whereas adaptive repetitive thinking, such as reflection, is a type of self-focus motivated by curiosity and openness (Trapnell \& Campell, 1999; Watkins, 2008). The contention that self-focus or self-awareness can differ in terms of motivation has, to our knowledge, not been examined to date in relation to visual (observer versus field) perspective. Therefore, another aim of our research was to examine how the tendency to engage in maladaptive versus adaptive repetitive thinking relates to visual perspective, and is the key question we address in Study 2. Our two studies examine the use of observer perspective in relation to a range of discrete emotion cues that vary in terms of valence and self-focus.

\section{Study 1}

In Study 1, we asked participants identified as high and low worriers to imagine and retrieve events related to discrete emotions, important events, and events related to word-cues. For each event generated, participants were asked to assess their visual perspective and to answer other relevant questions (e.g., age of the memories). We included events generated in response to emotion cues and requests for important events (likely to be high on personal significance and emotional impact) as well as events generated in response to word cues (likely to be low on personal significance). Discrete emotional states can differ in terms of self-awareness, motivational function, arousal, and self-relevance, which in turn can differentially influence phenomenological characteristics of remembered or imagined autobiographical events, such as visual perspective (Berntsen \& Rubin, 2006b; Levine \& Pizarro, 2004). Thus, although we failed to find an effect for worry in a previous study examining word-cued and spontaneously arising past and future thinking (Finnbogadottir \& Berntsen, 2011), it is possible that an effect of worry could be detected with regard to emotional and important events. For emotion cues, we chose two negative emotions we 
hypothesized could trigger avoidance in high worriers: afraid, as this emotion seems most related to the worry process, and ashamed, as this emotion involves evaluative, judgmental self-focus, which is a characteristic of maladaptive repetitive thinking such as worry (Watkins, 2008; Wong \& Moulds, 2012). We contrasted these negative emotions with two positive emotions: happy as a counterpart to afraid, in that both are considered as basic emotions by most theories (e.g., Power \& Dagleish, 2008), and proud as a counterpart to ashamed, because both are self-evaluative.

We expected that high worriers would report greater observer perspective compared with low worriers. Due to the nature of the cues, which vary in qualities such as valence and importance (e.g., word-cues versus a request for a highly fearful event), we expected to find interactions between cueing and trait worry, in that the differences between high and low worriers in terms of visual perspective would be greater for emotional and important events than for events generated in response to word cues. Furthermore, because the focus of worry is on feared future events, such differences in perspective might be even greater for future events than for past events. In line with previous findings, we expected field perspective to be more common than observer perspective, but observer perspective would be slightly more common for future than for past events (e.g., Finnbogadottir \& Berntsen, 2011). In terms of cueing, based on the previous literature (e.g., D'Argembeau \& Van der Linden, 2008; Nigro \& Neisser, 1983, but see Berntsen \& Rubin, 2006b), we expected that events related to the emotions pride and shame would evoke the most observer perspective, at least compared with word-cued events, in that these emotions imply self-awareness.

\section{Method}

\section{Design}

We examined past and future Mental Time Travel (MTT) in high and low worriers, cueing MTT with six different types of cues. Thus, the design is a 2 (high versus low worrier) 
x 2 (past versus future) x 6 (word-cued, afraid, happy, ashamed, proud, important event) mixed design. For both memories and future projections, participants recorded one event related to each discrete emotion (i.e., afraid, happy, ashamed, proud), a self-nominated most important event and five events generated in response to cue words. Thus, each participant recorded a total of 20 events, 10 for each temporal direction.

\section{Participants}

Forty-six Danish undergraduates (36 females, $M_{\text {age }} 23.5$ years; $S D=4.44$; range 20-45) participated in the study. Each participant was compensated with roughly $€ 20$.

A screening package was distributed in large undergraduate lectures at various departments (law, political science, English, psychology, theology) at Aarhus University in the period of December 2008 to February 2009. Filling out the screening package was voluntary, and 228 students chose to do so. The Penn State Worry Questionnaire (PSWQ; Meyer, Miller, Metzger, \& Borkovec, 1990) was used as a screening measure to identify individuals with high or low levels of worry. The PSWQ is a 16-item self-report questionnaire that measures individual differences in intensity and excessiveness of worry; total scores range from 16 to 80 . The PSWQ has excellent psychometric properties in both non-clinical and clinical populations (Molina \& Borkovec, 1994). In this study, the PSWQ demonstrated high internal consistency (Cronbach's $\alpha=.97$ for pre-measure and $\alpha=.95$ for post-measure). Individuals with PSWQ scores 60 and above were selected as high worriers, corresponding to the upper twenty scores on the scale (60-80) and roughly the top $20 \%$ of the screening sample. The criteria for selecting low worriers mirrored the criteria for high worriers, by defining low worriers as being the bottom twenty scores on the scale (16-36) corresponding roughly to the bottom $20 \%$ of the screening sample (see Delgado, Guerra, Perakakis, Mata, Pérez et al., 
2009, and Moulds, Kandris, \& Williams, 2007 for a similar procedure).

Of the 46 undergraduates accepting an invitation to participate in the study, we identified 24 as high worriers (22 females) and 22 as low worriers (14 females). The study was presented as a study examining autobiographical memories and future projections. As the study was conducted approximately one year after screening ${ }^{1}$, participants were asked to complete the PSWQ at the end of the study to check whether they could still be classified as high and low worriers. Although test-retest reliability for the PSWQ was high $(r=.92)$, high worriers had slightly lower scores on the PSWQ at the end of the study, with 10 of the high worriers drifting below the selection criteria for a high worrier, whereas low worriers had slightly higher scores at the end of the study, with four of the low worriers drifting above the selection criteria for a low worrier. We chose to exclude those 14 participants and only include those participants that could be classified as high or true low worriers on a reliable basis $^{2}$.

\section{Materials}

Booklet. Participants received booklets with instructions and a questionnaire for each type of event they were to record. The booklet was divided into two parts - one for recording future projections and one for recording memories. Instructions and questions for memories and future projections were the same, except for temporal reference. Participants started with future events to prevent the past events selected from determining the future events. The word-cues were interspersed with the recordings of emotional and important events in order to minimize carryover

\footnotetext{
${ }^{1}$ The delay between screening and start of the study was due to practical reasons, and is certainly not recommended, as even though trait measures such as the PSWQ are assumed to measure traits that are stable over time, regression towards the mean may occur.

${ }^{2}$ Note that including these participants in the analyses does not change the main findings.
} 
effect from one emotional event to another. In order to minimize the effects of the order in which the cues and events were presented, two orders of cues were created (with one being in reverse order from the other), and participants were randomly assigned to one of these two orders. Half of participants started with recording future projections in the original order of cues and thereafter recording memories in the reverse order, whereas the other half started with future projections with the reverse order of cues and thereafter autobiographical memories in the original order. We found no consistent order effects for any of the dependent variables.

Cues. The five cue words used to cue autobiographical memories and future projections were: snow, telephone, school, to bicycle, friend. These cue words are a subset of the cue words used in previous diary studies and relate to themes that are common in involuntary autobiographical memories in student samples and thus provide a representative sample of autobiographical memories as retrieved in everyday life (e.g., Berntsen \& Jacobsen, 2008; Finnbogadottir \& Berntsen, 2011). Instructions for word-cues were: Think back and describe the first memory you can think of in relation to this cue word: snow. The instructions for the emotion events were: Think back and describe one of the situations in your life, where you felt most proud. The instructions for the important events were: Think back and describe one of the most important events in your past. Instructions for future events were the same, except for temporal reference.

Questionnaire. The questions for each future projection are presented in Table 1. The questions assess various qualities of the future projection, such as phenomenological qualities (questions 1-5), self-relevance (questions 6-10), and the participant's age in the event. The questions were adapted from the Autobiographical Memory Questionnaire (AMQ; Rubin, Schrauf, \& Greenberg, 2003) and the Centrality of Event Scale (Berntsen \& Rubin, 2006a). The AMQ is a set of rating scales considered individually rather than being summed up, as 
they measure different aspects of autobiographical memory. The CES is a measure of perceived self-relevance of autobiographical events and their centrality for life-story and identity (Berntsen, Rubin, \& Siegler, 2011), and has been found to show good internal consistency ( $\alpha$ ranging .93 to .95; Berntsen \& Rubin, 2006a).

\section{Procedure}

The study was conducted in small groups. Participants were seated so that there was at least one empty seat between them, to minimize interference and ensure privacy. Participants received both verbal and written instructions in a group setting, with the main points repeated in their booklets. The experimenter started by explaining the task, the different event types, and the questions to answer for each event recorded. Participants were informed that they could withdraw their participation at any time during the study.

The experimenter carefully explained and provided examples of autobiographical memories and future projections, and explained the questions posed regarding each event. It was emphasized that within the past or the future conditions, participants should not record the same event twice, and if a previously retrieved/imagined event came to mind in response to another cue, they should retrieve/imagine a new event. The difference between memories/future projections of specific versus general events was also carefully explained and examples were provided; participants were told that both types of events could be recorded. The experimenter used emotionally neutral examples as illustrations. For word-cued memories and future projections, it was emphasized that participants could draw upon all kinds of personal experiences, important as well as unimportant, pleasant or unpleasant.

After the general instructions, participants were instructed to open their booklet and go through the tasks in the booklet at their own pace. At the end of the booklet, participants were 
asked to complete the PSWQ. Finally, participants were debriefed and thanked for their participation.

\section{Results}

Characteristics of the 32 participants included in the study are reported in Table 2. High and low worriers did not differ significantly in terms of age or gender distribution.

A total of 640 events were recorded, 20 for each participant. For the five word-cued events, mean scores were calculated for each participant across the five events for each temporal direction, and these means were used in the following statistical analyses.

Of the 639 events in which perspective ratings were made (1 missing), 220 (34.4\%) were reported to have been experienced completely from field perspective (a rating of 1), compared with $94(14.7 \%)$ that were experienced completely from observer perspective (a rating of 7$)$. Thus, in accordance with previous findings, field perspective was more common than observer perspective.

To analyze the characteristics of past and future events in relation to trait worry, a series of repeated-measures analyses of variance (ANOVA) were conducted, with two within-subjects factors (cueing, time) and one between-subjects factor (trait worry). When assumptions of sphericity were violated, we used a Greenhouse-Geisser correction, indicated by corrected degrees of freedom. In the following, we first report all the findings related to high versus low levels of worry. Second, we report the findings related to the two other factors, i.e., cueing and time. Here, we focus on the effects of these factors on Perspective ratings, in order to stay within the scope of the present study. However, we also summarize the main findings regarding the remaining dependent variables. As the number of dependent variables is large and because of the exploratory nature of the study, we use a significance level of $p<.01$, in order to decrease the likelihood of false positives. In order to avoid false negatives, in the light of our relatively small sample sizes, we 
choose not to use a standard Bonferroni correction (see also O'Keefe, 2003). Thus, our choice of adopting a significance level of $p<.01$ was made in order to strike a balance between Type 1 and Type 2 error.

\section{Effects of High versus Low Levels of Worry}

In accordance with our predictions, high worriers rated both their past and future events consistently more observer like (i.e., higher on perspective) than did low worriers, $F(1,29)=$ 19.77, $p<.001, \eta_{p}{ }^{2}=.41$ (Figure 1). This effect was found for both future and past events and across all types of cueing, as there were no interactions with cueing, $F(5,145)=2.04, p=.08, \eta_{p}{ }^{2}=$ .07 , or time, $F(1,29)=1.12, p=.30, \eta_{p}{ }^{2}=.04$.

The events reported by high versus low worriers did not differ significantly with regard to sensory vividness (see/hear), self-relevance (life story, importance, identity, reference point) intensity, specificity, distance in time or valence (all $F \mathrm{~s} \leq 3.43$, all $p \mathrm{~s}>.01$ ), or consequences ( $p=$ .02). For emotional intensity, the three-way interaction was significant $\left(F=3.84, p<.01, \eta_{p}{ }^{2}=.11\right)$. This effect reflected a significant two way interaction in the high worrier group between temporal direction and cueing, $F(5,115)=3.25, p<.01, \eta_{p}{ }^{2}=.12$, primarily caused by the important event being rated more intense in the future condition, as evinced by Tukey Post Hoc tests $(p<.05)$. Such two way interaction was not found in the low worrier group, $F(5,105)=1.2, p>.3$. All other interactions involving the factor worry were non-significant (all $F \mathrm{~s}<2.92$, all $p \mathrm{~s}>.01$ ).

\section{Effects of Time and Cueing on Observer Perspective}

When examining the use of visual perspective with repeated measures ANOVA, the main effect of cueing was not significant, when employing an alpha level of $.01, F(5,145)=2.31, p=$ 
$.047, \eta_{p}^{2}=.07$ (proud: $M=3.44, S D=2.06$; ashamed: $M=3.03, S D=2.14 ;$ important event $: M=$ 3.98, $S D=2.02 ;$ word-cue: $M=3.52, S D=1.32 ;$ happy: $M=3.16, S D=2.03 ;$ afraid: $M=3.11, S D$ $=2.09$, see Figure 1 for the mean levels across cueing, temporal direction and groups). The main effect of temporal direction was not significant, $F(1,29)=3.52, p=.071, \eta_{p}{ }^{2}=.11$ (future events: $M$ $=3.58, S D=1.98$; past events: $M=3.17, S D=1.91)$, and the interaction between cueing and temporal orientation was not significant, $F(3.6,104.2)=.70, p=.58, \eta_{p}{ }^{2}=.02$.

Again, because the main purpose of the present study was to examine the effects of worry in terms of visual perspective, we will only briefly report our findings related to the main effects of time and cueing for the other dependent variables, as well as interactions between these two factors. Overall, we replicate many previous findings for differences between past and future MTT. Memories of past events were rated higher on sensory vividness, $F(1,30)=15.52, \mathrm{p}<.001, \eta_{p}{ }^{2}=$ .34 , whereas representations of future events were rated higher on measures of self-relevance, or personal importance, relevance to life story, and the degree to which one had thought of the consequences of the event (all $F \mathrm{~s} \geq 23.97$, all $p \mathrm{~s}<.001$, all $\eta_{p}{ }^{2} \geq .44$ ). For identity and reference point this difference approached but did not attain significance (both $F s \geq 6.00, p s \geq .01, \eta_{p}{ }^{2} \geq .17$ ). Furthermore, memories were more specific than future event representations, $F(1,30)=24.85$, $\mathrm{p}<$ $.001, \eta_{p}{ }^{2}=.45$. Past and future events did not differ in terms of valence, intensity, or age of event (all $F \mathrm{~s} \leq 4.67$, all $p \mathrm{~s} \geq .04$, all $\eta_{p}^{2} \leq .14$ ).

For dependent variables other than perspective, there was a main effect of cueing on all dependent variables (all $F_{\mathrm{S}} \geq 5.35$, all $p \mathrm{~s} \leq .001$, all $\eta_{p}{ }^{2} \geq .15$ ), except specificity and age of event (both $F s \geq 3.06, p s \geq .01, \eta_{p}{ }^{2} \geq .14$ ). These main effects of cueing were largely due to substantial differences in ratings of word-cued versus ratings of important events and events cued by positive emotion. The general pattern for the main effect of cueing appeared to be that joy, pride, and important events were rated more positive, and higher on measures of self-relevance, intensity, and 
vividness compared to fear, shame, and word-cued events (see Appendices A and B for details on the means and standard deviations).

Finally, the interaction between cueing and temporal direction was significant for specificity, life story, importance and age of event (all $p \mathrm{~s} \leq .004$ ), largely consistent with previous work comparing word cued and important events in the two temporal directions (Berntsen \& Bohn, 2010). These interactions will not be analyzed in detail because they are not central to the present focus on worry and visual perspective.

\section{Discussion}

We found a more pronounced use of observer perspective in high worriers across differently cued events, and for both past and future events. As the effect of worry on visual perspective was not qualified by interactions with cueing or temporal direction (counter to our predictions), the findings suggest that high worriers may exhibit a consistent tendency towards using more observer perspective, when remembering and imagining autobiographical events.

We found no differences between high and low worriers on the other dependent variables. Accordingly, greater use of observer perspective in the high worrier group compared with the low worrier group cannot be explained in terms of differences in sensory vividness, age of events, intensity or valence of the events, memory characteristics that tend to covary with visual perspective (e.g., Berntsen \& Rubin, 2006b; Nigro \& Neisser, 1983; Talarico \& Rubin, 2003).

The greater use of observer perspective among high worriers may have many possible explanations that are likely to be complementary, rather than mutually exclusive. First, high worriers may use observer perspective to reduce emotional experience in relation to the imagined or remembered event (e.g., Berntsen \& Rubin, 2006b; Finnbogadottir \& Berntsen, 2011). Second, maladaptive repetitive thinking, such as worry, has been defined as abstract, evaluative thinking 
about the meaning, causes and consequences of events (Watkins, 2008, p. 188). Thus, another possible explanation is that individuals with a tendency to worry may employ more observer perspective because they are thinking more about the self-related meaning of the events they are remembering or imagining (Libby \& Eihbach, 2011). Third, the greater use of observer perspective may reflect that high worriers engage in self-evaluation to a greater extent than low worriers, as observer perspective is more likely to be adopted when analyzing how the self relates to some ideal standard (Clark \& Wells, 1995; Clark, 2001; Hung \& Mukhopadhyay, 2012; Kuyken \& Howell, 2006). Following this line of explanation, one might have expected greater differences in visual perspective between high and low worriers for the self-evaluative emotions, relative to other emotions. However, there was no interaction between trait worry and cueing on visual perspective. This finding may suggest that self-evaluation is not a causal factor in determining visual perspective, or, alternatively, that high worriers have a more general tendency towards selfevaluation, regardless of the type of event they are imagining or remembering. Fourth, rather than explaining observer perspective as a function of worry, the causal relation may be the reverse so that the use of observer versus field perspective is a causal factor for the worry process, or at least a contributing factor. Obviously, the present study does not allow us to determine the direction of causality.

The present findings differ from our previous study (Finnbogadottir \& Berntsen, 2011) in which no reliable main effect of worry was found on visual perspective. One possible explanation may be that the present study used emotion cues and that the setup of the present study, in which word-cued events were interspersed between requests for emotional events, differed from Finnbogadottir and Berntsen (2011). Nevertheless, it should also be noted that in our previous study, the means for visual perspective were in the expected direction, and for past events the effect of worry on visual perspective approached significance. 
Although not being the main focus of the present study, we found a number of main effects of cueing and temporal direction as well as some interactions between these factors: Past MTT was rated more sensory vivid and more specific compared to future MTT, whereas future MTT was rated higher on measures of self-relevance or personal significance, although for identity and reference point this difference only approached significance. These findings are consistent with previous work showing that future MTT involves less sensory imagery and relies more on schematized knowledge, compared to past MTT (e.g., Berntsen \& Bohn, 2010). However, in contrast to previous findings (e.g., Spreng \& Levine, 2006; Berntsen \& Bohn, 2010), past MTT did not refer to temporally more distant events than future MTT and was not rated as being less positive than future MTT, potentially due to the extensive use of emotion cues in the present study. For dependent variables other than perspective, there was a main effect of cueing on all dependent variables, except specificity and age of event. These main effects of cueing were largely due to substantial differences in ratings of word-cued versus ratings of important events and events cued by positive emotion. The general pattern for the main effect of cueing appeared to be that joy, pride, and important events were rated more positive, and higher on measures of self-relevance, intensity and vividness compared to fear, shame, and word-cued events. These main effects of cueing can be seen as consistent with a positivity bias in autobiographical memory (Rasmussen \& Berntsen, 2009). The interaction between cueing and temporal direction was significant for specificity, life story, importance and age of event, which agrees with earlier research examining characteristics of past and future MTT when cued by words versus requests for important events (e.g., Berntsen \& Bohn, 2010). Finally, we found a three-way interaction for intensity, in that important future events were rated as more extreme than important past events in the high worrier group, but not in the low worrier group. 
To summarize the findings from Study 1 that are central to the present focus on worry and perspective, we found systematic differences between high versus low levels of worry with regard to the use of observer perspective. Across both temporal directions and across cueing conditions, a high level of worry was associated with more observer perspective.

In spite of these consistent effects, the present study also has a number of limitations. First, the participants in the study were highly selected groups of high and low worriers, corresponding to the upper and lower twenty percent of the population screened. Second, sample sizes were quite small, which may have reduced the power of the study in detecting smaller effects. Third, choosing an alpha correction of .01 in order to avoid type 2 errors may have decreased the likelihood of detecting smaller effects. Notably, we failed to find a main effect of cueing on visual perspective, and it should be noted that the main effect of cueing would have been significant, had we chosen a significance level of .05. Accordingly, this effect warrants examination in future studies. Also, we found no effect of temporal direction, although a numerical difference was found in the expected direction. Fourth, because of our decision to not use a more stringent alpha correction, such as a Bonferroni correction, the results need to be replicated with a larger sample before more definitive conclusions can be made. Finally, we did not include measures of depressive or anxious symptoms; therefore, we cannot rule out the possibility that the findings are due to other differences between the groups of high and low worriers, such as anxiety.

\section{Study 2}

The main purpose of Study 2 was to examine the use of observer perspective in relation to worry and other thinking styles, as well as individual differences related to anxiety and depression. To do so, we instructed healthy undergraduates to retrieve memories related to discrete emotions and to answer questions regarding each event. A week later, the participants returned and completed 
measures of individual differences that assessed negative affect and thinking styles, adaptive and maladaptive.

For cueing autobiographical memories, we chose four events related to distinct emotions: shame as a negative self-evaluative event, and pride as a positive self-evaluative counterpart, consistent with Study 1. We contrasted these emotions with positive and negative other-evaluative emotions, contempt and admiration, as D'Argembeau and Van der Linden (2008) found that selfevaluative emotions, regardless of valence, evoked more observer perspective than the otherevaluative emotions. In this way we could examine whether a tendency to use observer perspective may be less apparent for events involving evaluation of others.

At the memory level, we expected field perspective to be more common than observer perspective. We also expected self-evaluative emotions to evoke more observer perspective compared with other-evaluative emotions.

In order to examine individual differences, we included measures of different thinking styles, some of which are considered adaptive (e.g., reflection, reappraisal) and some maladaptive (e.g., worry, rumination), in order to examine how the tendency to engage in maladaptive versus adaptive thinking styles relates to visual perspective, as they may differ in type of self-focus. Furthermore, we included measures of depression, social anxiety, and Posttraumatic Stress Disorder (PTSD), as researchers have found greater use of observer perspective in relation to these disorders (e.g., McIsaak \& Eich, 2004; Wells, Clark, \& Ahmad, 1998; Williams \& Moulds, 2007). We also included measures of state and trait anxiety. Participants also completed measures of vividness of visual imagery (Marks, 1973), private self-consciousness (Scheier \& Carver, 1985), and a measure of event centrality (Berntsen \& Rubin, 2006a), which will not be reported in the Results section, as they are not relevant to the focus of the present study. We expected measures related to maladaptive 
repetitive thinking (e.g., rumination, worry), general anxiety, depression, PTSD, and social anxiety to be positively associated with use of observer perspective.

\section{Method}

\section{Participants}

A total of 151 psychology undergraduates at Aarhus University (128 females, $\mathbf{M}_{\text {age }}=23.96$, $S D=3.87$, range 20-46) participated in the study as a part of a course in research methods in psychology. Participants were told that they were participating in a study on autobiographical memory, and that the current study was a study on memories of different types of events. The data were collected in a group session in a large auditorium, where the students regularly attended lectures in the course. Participants were informed that their responses were anonymous and that they were free to withdraw at any given point during the study.

\section{Design}

We used a 4 (pride, shame, admiration, contempt) within-subjects design with the order of event-type counterbalanced across participants by creating four different orders ${ }^{3}$. In total, each participant retrieved and recorded four autobiographical memories.

\section{Materials}

Memory Booklet. Participants were presented with a booklet with instructions and a questionnaire for each event they were to record. Each event and associated questions was included

\footnotetext{
${ }^{3}$ There was a main effect of order on perspective for the event cue pride, $F(3)=4.39, p<.01$. Posthoc tests revealed that the group that received the cue pride last in the booklet retrieved this memory with more field perspective $(M=2.18)$ than the group that received pride as a first $(M=$ $3.47)$ or second $(M=3.59)$ cue, both $p$ s $<.01$.
} 
in its own section in the booklet, separated by ratings of current mood and tension. The booklet started with a brief written introduction to the study, followed by the first rating of current mood and tension. Next in the booklet was a brief written instruction for the memory task. The remainder of the booklet was structured as described in the procedure for recording memories, with participants asked to retrieve an event, write details, and answer the questions described in the Memory Questionnaire.

Event Cues. The instructions for pride and shame were: Think back and describe with a short title one of the situations in your life, where you felt most proud/ashamed. The instructions for admiration and contempt were: Think back and describe with a short title one of the situations in your life, where you felt a deep admiration/contempt for another person.

Observer Perspective and Other Memory Characteristics. For each event, participants were asked to rate their level of observer perspective in the same way as in Study 1 (see Question 3 in Table 1). In addition, they answered other questions addressing the qualities and characteristics of the four memories, as well as measured their retrieval time and answered questions related to their current mood and tension. However, these additional measures are not relevant to the present focus of the study and will not be reported here.

\section{Individual Differences Measures.}

The Penn State Worry Questionnaire (PSWQ). The PSWQ (Meyer et al., 1990) is a 16 item self-report questionnaire that measures individual differences in intensity and excessiveness of worry. The PSWQ has excellent psychometric properties in both non-clinical and clinical populations (Molina \& Borkovec, 1994) showing good internal consistency, test- 
retest reliability and validity (Meyer et al., 1990). In this study, the internal consistency for the PSWQ was $\operatorname{good}(\alpha=.92)$.

The Beck Depression Inventory - Second Edition (BDI-II). The BDI-II (Beck, Steer, \& Brown, 1996) is a 21-item instrument that asks participants to indicate how they have felt over the past two weeks. Each item assesses a particular symptom of major depression and contains four response options, ranging from 0 to 3, with higher scores indicating a higher level of depressive symptomatology. The BDI-II has been found to show good internal consistency $(\alpha=.91)$, test-retest reliability $(r=.93)$, and criterion-related validity, strongly correlating ( $r=.83)$ with structured clinical interview scores (Beck et al., 1996). In this study, the internal consistency for the BDI-II was $\operatorname{good}(\alpha=.86)$.

The Rumination-Reflection Questionnaire (RRQ). The rumination subscale of the RRQ (Trapnell \& Campbell, 1999) contains 12 items rated on 5-point Likert scales with higher scores indicating a greater degree of rumination. The rumination subscale focuses on stressor-related rumination, with items referring to negative episodes and situations. The rumination subscale showed good internal consistency in the current study $(\alpha=0.84)$. The reflection subscale of the RRQ also contains 12 items rated on 5-point Likert scales, with higher scores indicating a greater degree of reflection. The reflection subscale focuses on reflections on the self, motivated by pleasurable, intrinsic interest in abstract or philosophical thinking. The RRQ has been found to have good internal consistency (Trapnell \& Campbell, 1999). The reflection subscale showed good internal consistency in the current study $(\alpha=.91)$. 
State-Trait Anxiety Inventory (STAI). The STAI (Spielberger, Gorsuch, Lushene, Vagg, \& Jacobs, 1977) is a self-report measure of both trait and state anxiety. Each subscale consists of 20 questions rated on a 4-point Likert scale. The STAI possesses good internal consistency and testretest reliability (Spielberger et al., 1983). In the current sample the internal consistency for both scales was good (STAI-state, $\alpha=.940 ;$ STAI-trait, $\alpha=.941)$.

Social Interaction Anxiety Scale (SIAS). The SIAS (Mattick \& Clarke, 1998) is a 19-item instrument that assesses fears of general social interaction, such as making conversation or eye contact, rated on a 5-point Likert scale.The SIAS has been found to have high internal consistency and to discriminate between individuals suffering from social phobia and individuals suffering from other anxiety disorders (Mattick \& Clarke, 1998). In the current sample the SIAS showed good internal consistency $(\alpha=.91)$.

PTSD Check List (PCL). The PCL (Weathers, Litz, Huska, \& Keane, 1994) has participants rate 17 symptoms of PTSD, on a scale from 1 (not at all) to 5 (extremely). The PCL has been found to show good psychometric properties, with high internal consistency and test-retest reliability, and favorable convergent and discriminant validity (Blanchard, Jones-Alexander, Buckley, \& Forneris, 1996; Conybeare, Behar, Newman, \& Borkovec, 2012). In the current sample the PCL showed good internal consistency $(\alpha=.90)$.

Emotion Regulation Questionnaire (ERQ). The ERQ (Gross \& John, 2003) assesses habitual use of two types of emotion regulation strategies, reappraisal, which is considered adaptive, and suppression, which is considered less adaptive. The reappraisal subscale consists of six items and the suppression subscale consists of four items. The scales possess acceptable-to-good internal 
consistency and correlate differently with negative affect versus well-being (Gross \& John, 2003). In the current sample both subscales showed acceptable internal consistency (reappraisal: $\alpha=.79$, suppression: $\alpha=.77)$.

\section{Procedure}

The study took place on two days one week apart. On the first day, participants recorded autobiographical memories, and on the second day participants completed individual difference measures.

On the first day, the four versions of the booklet were distributed evenly in the auditorium where lectures in the course took place. Participants were told not to open the booklet but to complete the various tasks at the same pace, following the instructions of the principal experimenter. The experimenter started by giving a brief overview of the procedure for the study. Then, the ratings scales for current mood and tension were explained. Next, the experimenter explained what autobiographical memories are and gave examples of specific, categorical and extended autobiographical memories. Participants were told to record only specific memories.

Next, the experimenter explained the procedure for recording memories, which was as follows: When the experimenter instructed them to do so, participants turned to the next page asking them to retrieve a certain type of event, with the event-type covered by an adhesive label. Participants were instructed to remove the adhesive label upon turning the page, then write down a short title describing the memory. Participants had two minutes to complete this part. Next, the experimenter instructed them to turn the page and record as many details from the memory as they could possibly think of, and number the details sequentially. Participants had three minutes to complete this part, and were told to use all three minutes. The experimenter then instructed participants to turn to the next page where they were to answer questions regarding the event, such 
as rating visual perspective. Participants had five minutes to complete this part. All of these steps were carefully explained and examples were provided using a visual presentation. This procedure was repeated for each event. Once participants had gone through the booklet, they were given a break before continuing with another memory task, which was related to a different research project on executive processes and thus is not described here.

On the second day, one week later, participants received a general instruction to complete the individual differences measures, and were then told to go through those measures at their own pace and to call for the experimenters if they had specific questions. Participants were debriefed approximately a month later.

\section{Results}

In the following section, we first report information on participants. Second, we report findings related to the factor cueing. We limit this analysis to the effects of cueing on Perspective ratings, in order to stay within the scope of the present study. Third, we report correlations between perspective and measures of negative affect and thinking styles. When assumptions of sphericity were violated, we used a Greenhouse-Geisser correction, indicated by corrected degrees of freedom. As in Study 1, we use a significance level of $p<.01$, in order to strike a balance between Type 1 and Type 2 error.

\section{Participant Characteristics}

Means and standard deviations for individual differences measures are presented in Table 3. 


\section{Visual Perspective}

In line with previous findings, field memories were much more common than observer memories, in that of the 562 memories where ratings of visual perspective were completed (ratings of 42 memories were missing), 188 (33.5\%) were retrieved completely from field perspective (a rating of 1$)$, whereas only $22(3.9 \%)$ memories were retrieved completely from observer perspective (a rating of 7).

To examine whether memories related to the four emotions differed in terms of visual perspective, we ran a repeated measures ANOVA with one within-subjects factor (emotion). Using the corrected alpha level, we found no main effect for emotion, $F(3,357)=3.03, p=.03, \eta_{p}{ }^{2}=.03$ (shame: $M=3.15, S D=.18 ;$ pride: $M=2.96, S D=.17 ;$ admiration: $M=2.52, S D=.16 ;$ contempt: $M=2.85, S D=.18)$.

\section{Correlations with Measures of Negative Affect and Thinking Styles}

Table 4 reports the correlations between measures of individual dispositions and ratings of visual perspective for each event, as well as correlations with mean ratings of visual perspective calculated across the four events (fourth column). Across the four events (Table 4, fourth column), individual difference measures related to negative affect and more maladaptive types of repetitive thinking (e.g., rumination, worry) were associated with greater use of observer perspective, whereas measures of adaptive repetitive thinking (e.g., reflection) were associated with reduced observer perspective (i.e., greater use of field perspective). The only significant correlations were those involving measures of social anxiety and general anxiety (trait), as well as rumination. The correlations involving trait worry and reflection equaled or exceeded $(r=.20)$, although they were not significant. When examining the individual events (Table 4, columns 1-3), only the event involving admiration showed the same pattern consistently, with social anxiety, general anxiety 
(state and trait) and posttraumatic symptoms significantly associated with more observer perspective. Furthermore, the association between reflection and reduced observer perspective (i.e., greater use of field perspective) was significant only for the event involving contempt.

We then ran a series of six linear regression analyses to examine whether the associations found between the mean visual perspective and each individual differences measure were being driven by negative affect; that is, by levels of anxiety and depression. Each regression analysis had observer perspective (averaged score) as the dependent variable. For each analysis, trait anxiety, state anxiety and depression scores were always included. In addition, we included the scores from the SIAS, ERQ-Reappraisal, ERQ-Suppression, PSWQ, RRQ-Rumination, and RRQ-Reflection separately, that is one of them for each of the six analyses, in order to see if each of them would be a significant predictor of observer perspective once we controlled for negative affect, in terms of trait anxiety, state anxiety and depression scores. In these analyses, only the RRQ-Reflection reflection score showed a significant effect $\left(\beta=-27, p<.01 ; R^{2}=.14\right)$.

\section{Discussion}

The findings from Study 2 suggest that negative affect is generally associated with a greater tendency towards observer perspective. When examining the correlations, both measures of negative affect and maladaptive thinking styles, such as worry and rumination, were associated with a greater tendency towards observer perspective, although the correlations were most consistent for the event involving admiration. The results from the regression analyses predicting visual perspective as averaged across the four events suggest that the association between maladaptive thinking styles and greater use of observer perspective may be partially due to their mutual association with negative affect, as measures of maladaptive thinking styles were not significant 
predictors of mean visual perspective once negative effect, in terms of depression, trait anxiety and state anxiety, was controlled for.

Conversely, the correlations suggested that the tendency to engage in reflection was associated with reduced observer perspective (and thus with greater tendency towards field perspective) although this correlation was significant only for the event involving contempt. The results from the regression analyses predicting perspective averaged across the four events, suggested that the association between reflection and reduced observer perspective was independent of negative affect, as reflection remained a significant predictor of visual perspective once negative affect was controlled for.

At the memory level, field perspective was more common than observer perspective. This was in line with our predictions as well as previous findings. We did not find support for our hypotheses that the self-evaluative emotions of pride and shame would evoke more observer perspective than the other-evaluative emotions, as the main effect of emotion was not significant. It should be noted, however, that had we adopted a significance level of .05 , the main effect of emotion on visual perspective would have achieved significance.

The study had several limitations. First, the correlations we found were relatively small, and with a stricter control of the alpha level (i.e., Bonferroni correction), they would no longer be significant. This calls for the need to replicate the results before drawing any strong conclusions. Second, we obtained a number of correlations that were .20 and above, which were not significant at the significance level of .01, yet might be worth reexamining in future research. Third, the study used a sample of, mostly female, undergraduates, which may limit the generalizability of the findings to general and clinical populations. 


\section{General Discussion}

Study 1 showed that high worriers reported more observer perspective than low worriers, across different cue types, that is, for emotional versus unemotional event as well as for remembered versus imagined events. The findings from Study 2 suggested that negative affect is associated with greater tendency towards observer perspective, and that the association between maladaptive thinking styles, such as worry and rumination, and greater use of observer perspective may be partially due to their mutual association with self-reported anxiety and depressive symptoms. At the same time, Study 2 showed that the tendency to engage in reflection was associated with a reduced observer perspective; thus, a greater tendency towards field perspective. This association appeared to be independent of negative affect according to the multiple regression analysis.

Taken together, the findings suggest that the greater use of observer perspective among the high worriers in Study 1, may have been due to the higher level of negative affect in this group rather than due to worry per se. However, further research is needed to examine this explanation, as we did not measure negative affect in Study 1.

The correlations found in Study 2 were most consistent for the event involving admiration, which was counter to our expectation that stronger correlations would be found for the selfevaluative events. This unexpected finding should be examined further in future studies, both in order to see whether it replicates, and to examine why an event involving admiration of another person evokes retrieval from observer perspective for individuals high on negative affect and maladaptive thinking styles.

Although the correlations found in Study 2 were modest at best, the findings add to the existing literature on visual perspective by showing that negative affect is associated with greater use of observer perspective, whereas a tendency towards adaptive thinking styles, such as reflection, 
is associated with greater use of field perspective. The findings may be seen as consistent with the view that maladaptive repetitive thinking, such as rumination, is motivated by anxious or fearful/avoidant type of self-focus, whereas adaptive repetitive thinking, such as reflection, is motivated by a curious self-focus (Trapnell \& Campbell, 1999; see also Watkins, 2008). It may be that the vantage perspective one adopts during remembering and imagining autobiographical events is affected by the type of self-focus one adopts or, alternatively, that adopting a curious versus fearful self-focus may be mediated through adopting field versus observer perspective during autobiographical remembering. Future studies should examine whether the observed associations between negative affect and visual perspective may be due to the type of self-focus adopted (e.g., Wells \& Papageorgiou, 1999).

In line with previous research we found that, in general observer perspective was less common than field perspective. In Study 1 we did not replicate previous findings that future projections are rated more observer-like than autobiographical memories, in that the main effect of temporal direction was not significant, although a numerical difference was obtained in the expected direction. In both studies, the effect of cueing on visual perspective was not significant. That said, the main effect of cueing in both studies would have been significant, had we adopted a significance level of .05 instead of .01. Thus, it would be worth examining further the effects of different types of emotion on visual perspective.

The two studies had a number of limitations. For Study 1 the sample size was moderate, which may have limited the ability to detect smaller effects of trait worry. Also, as the high and low worriers had to be selected to the conditions, as opposed to randomly assigned, the differences between the two conditions on visual perspective may have been due to other differences between the groups than the differing levels of worry tendency, such as a broader tendency for experiencing negative affect as suggested by findings in Study 2. Additionally, gender distribution was uneven 
across conditions, which raises the possibility that gender differences might have driven the difference between high and low worriers on visual perspective. However, we consider this as being unlikely since previous research has, in general, not found a greater propensity among women to use observer perspective (Rice, 2010).

Furthermore, it should be mentioned that in Study 1 we do not replicate the previous finding (Finnbogadottir \& Berntsen, 2011) that high worriers relative to low worriers rated events probed with word-cues lower on measures of self-relevance. This outcome may be due to differences in the procedure of the Study 1 and the previous study, as in the present study word-cues were interspersed between requests for important and highly emotional events, whereas in our previous study they were not. This methodological variation may have affected participants' ratings of wordcued events in the present study.

A limitation of Study 2 is the fact that the correlations were not strong, and thus most of the variance in visual perspective remained unexplained. Furthermore, with a stricter correction for multiple tests, most of the significant correlations would no longer be significant. Perhaps stronger correlations would have been obtained if the events cued had tapped better onto the current concern most strongly related to the respective individual difference measure (i.e., sampling traumatic events in relation measures of PTSD symptoms; Harvey, Watkins, Mansell, \& Shafran, 2004). Another limitation of Study 2 is that the correlations were most consistent for the event involving admiration, although for the other events the correlations were in the same direction.

Both studies used undergraduate samples, which may limit the generalizability of the findings to clinical populations. Also by using a significance level of $p<.01$ in both studies, we may have increased the likelihood of false negatives, for instance for the main effect of cueing in both studies. Furthermore, by not choosing a more stringent alpha correction, such as a Bonferroni correction, the results of both studies need to be replicated before too far-reaching conclusions are warranted. 
Notwithstanding these limitations, the present studies add valuable new knowledge to the literature on observer perspective and anxiety. The findings show that high levels of maladaptive thinking and negative affect are associated with using more observer perspective when imagining and remembering autobiographical events across a range of emotions.

Future studies should examine further the nature of the relation between self-focus and perspective, as well as between perspective and emotional response in order to pinpoint when, and how observer perspective is adaptive or maladaptive. When is observer perspective associated with increases in anxiety, as suggested by the social anxiety literature, and when does it serve to reduce emotion, as suggested by the anger management literature? It may be that the nature of the relation with observer perspective depends on the type of emotion or event under study (e.g., Hung \& Mukhopadhyay, 2012; Nigro \& Neisser, 1983) or subtle differences between studies in how observer perspective is conceptualized or measured (e.g., Kross et al., 2005; Rice \& Rubin, 2011). Importantly, future studies should make connections between the different literatures on visual perspective. For instance, if in normal samples observer perspective accentuates change (Libby et al., 2005), affects attributions (Frank \& Gilovich, 1989), and affects behavior (Libby, Shaeffer, Eibach, \& Slemmer, 2007), how are these outcomes manifested in clinical and subclinical populations characterized by greater reliance on observer perspective (e.g., Kuyken \& Howell, 2006)? In short, future research should attempt to better integrate the cognitive, social, and clinical literatures on observer perspective, both in order to better understand everyday mechanisms of visual perspective in autobiographical remembering and to examine to what extent these mechanisms apply to populations characterized by emotional disorders. 


\section{References}

Barlow, D. H. (2002). Anxiety and its disorders: The nature and treatment of anxiety and panic (2nd ed.). New York, US: Guildford Press.

Beck, A.T., Steer, R.A., \& Brown, G.K. (1996). Beck Depression Inventory Manual (2 ${ }^{\text {nd }}$ ed.). San Antonio: The Psychological Corporation.

Berntsen, D., \& Bohn, A. (2010). Remembering and forecasting: The relation between autobiographical memory and episodic future thinking. Memory and Cognition, 38, 265-278.

Berntsen, D., \& Jacobsen, A. S. (2008). Involuntary (spontaneous) mental time travel into the past and future. Consciousness \& Cognition, 17, 1093-1104.

Berntsen, D., \& Rubin, D. C. (2006a). The centrality of event scale: A measure of integrating a trauma into one's identity and its relation to post-traumatic stress disorder symptoms. Behaviour Research and Therapy, 44, 219-231.

Berntsen, D., \& Rubin, D. C. (2006b). Emotion and vantage point in autobiographical memory. Cognition \& Emotion, 20, 1193-1215.

Berntsen, D., Rubin, D.C., \& Siegler, I.C. (2011). Two versions of life: Emotionally negative and positive life events have different roles in the orginization of life story and identity. Emotion, 11, 1190-1201.

Blanchard, E. B., Jones-Alexander, J., Buckley, T. C., \& Forneris, C. A. (1996). Psychometric properties of the PTSD checklist (PCL). Behaviour Research and Therapy, 34, 669-673.

Borkovec, T. D., Alcaine, O. M., \& Behar, E. (2004). Avoidance theory of worry and generalized anxiety disorder. In R. G. Heimberg, C. L. Turk \& D. S. Mennin (Eds.), Generalized anxiety disorder: Advances in research and practice (pp. 77-108). New York, US: Guildford Press. 
Clark, D. M. (2001). A cognitive perspective on social phobia. In W. Ray Crozier and Lynn E. Alden, International handbook of social anxiety: Concepts, research and interventions relating to the self and shyness (pp. 405-430). Chichester: John Wiley \& Sons Ltd.

Clark, D. M., \& Wells, A. (1995). A cognitive model of social phobia. In R. Heimberg, M. Liebowitz, D. A. Hope, \& F. R. Schneier (Eds.), Social phobia: Diagnosis, assessment and treatment. (pp. 69-93). New York: Guildford Press.

Conybeare, D., Behar, E., Newmann, M.G., \& Borkovec, T.D. (2012). The PTSD checklist Civilian version: Reliability, validity, and factor structure in a nonclinical sample. Journal of Clinical Psychology, 68, 699-713.

Crawley, S., \& French, C. (2005). Field and observer viewpoint in remember-know memories of personal childhood events. Memory, 13, 673-681.

Cribb, G., Moulds, M. L., \& Carter, S. (2006). Rumination and experiential avoidance in depression. Behaviour Change, 23, 165-176.

D’Argembeau, A., Comblain, C., \& Van der Linden, M. (2003). Phenomenal characteristics of autobiographical memories for positive, negative, and neutral events. Applied Cognitive Psychology, 17, 281-294.

D’Argembeau, A., \& Van der Linden, M. (2008). Remembering pride and shame: Selfenhancement and the phenomenology of autobiographical memory. Memory, 16, 538-547.

Delgado, L. C., Guerra, P., Perakakis, P., Mata, J. L., Pérez, M. N., \& Mila, J. (2009). Psychophysiological correlates of chronic worry: Cued versus non-cued fear reaction. International Journal of Psychophysiology, 74, 280-287. 
This article may not exactly replicate the final version published in the APA journal. It is not the copy of record. A definitive version was subsequently published in Psychology of Consciousness: Theory, Research, and Practice, 1, $387-$ 406. Link to the article: http//dx.doi.org/10.1037/cns0000029 (C) 2014 APA

Finnbogadottir, H., \& Berntsen, D. (2011). Involuntary and voluntary mental time travel in high and low worriers. Memory, 19, 625-640.

Frank, M. G., \& Gilovich, T. (1989). The effect of memory perspective on retrospective causal attributions. Journal of Personality and Social Psychology, 57, 399-403.

Giorgiou, J. M., Sanflippo, J., Kleiman, E., Reilly, D., Bender, R. E., Wagner, C. A., Liu, R. T., Alloy, L. B. (2010). An experiential avoidance conceptualization of depressive rumination: Three tests of the model. Behaviour Reserarch and Therapy, 48, 1021-1031.

Gross, J. J., \& John, O. P. (2003). Individual differences in two emotion regulation processes: Implications for affect, relationships, and well-being. Journal of Personality and Social Psychology, 85, 348-362.

Harvey, A., Watkins, E., Mansell, W., \& Shafran, R. (2004). Cognitive behavioural processes across psychological disorders. A transdiagnostic approach to research and treatment. UK: Oxford University Press.

Holmes, E. A., Coughtrey, A. E., \& Connor, A. (2008). Looking at or through rose-tinted glasses? Imagery perspective and positive mood. Emotion, 8, 875-879.

Hung, I. W., \& Mukhopadhyay, A. (2012). Lenses of The Heart: How Actors' and Observers' Perspectives Influence Emotional Experiences. Journal of Consumer Research, 38, 11031115.

Kross, E., Ayduk, O., \& Michel, W. (2005). When asking „why“ does not hurt. Distinguishing rumination from reflective processing of negative emotions. Psychological Science, 16, 709715. 
This article may not exactly replicate the final version published in the APA journal. It is not the copy of record. A definitive version was subsequently published in Psychology of Consciousness: Theory, Research, and Practice, 1, $387-$ 406. Link to the article: http//dx.doi.org/10.1037/cns0000029 (C) 2014 APA

Kuyken, W. \& Howell, R. (2006). Facets of autobiographical memory in adolescents with major depressive disorder and never-depressed controls. Cognition \& Emotion, 20, 466-487.

Levine, L. J., \& Pizarro, D. A. (2004). Emotion and memory research: A grumpy overview. Social Cognition, 22, 530-554.

Libby, L. K., \& Eihbach, R. P. (2011). Self-enhancement or self-coherence? Why people shift visual perspective in mental images of the personal past and future. Personality and Social Psychology Bulletin, 37, 714-726.

Libby, L. K., Eibach, R. P., \& Gilovich, T. (2005). Here's looking at me: The effect of memory perspective on assessments of personal change. Journal of Personality and Social Psychology, 88, 50-62.

Libby, L. K., Shaeffer, E. M., Eibach, R. P., \& Slemmer, J. A. (2007). Picture yourself at the polls: Visual perspective in mental imagery affects self-perception and behavior. Psychological Science, 18, 199-203.

Marks, D. F. (1973). Visual imagery differences in the recall of pictures. British Journal of Psychology, 64, 17-24.

Mattick, R. P., \& Clarke, J. C. (1998). Development and validation of measures of social phobia scrutiny fear and social interaction anxiety. Behaviour Research and Therapy, 36, 455-470.

McIsaak, H. K., \& Eich, E. (2002). Vantage point in episodic memory. Psychonomic Bulletin \& Review, 9, 146-150.

McIsaak, H. K., \& Eich, E. (2004). Vantage point in traumatic memory. Psychological Science, 15, $248-253$. 
This article may not exactly replicate the final version published in the APA journal. It is not the copy of record. A definitive version was subsequently published in Psychology of Consciousness: Theory, Research, and Practice, 1, $387-$ 406. Link to the article: http//dx.doi.org/10.1037/cns0000029 (C) 2014 APA

Meyer, T. J., Miller, M. L., Metzger, R. L., \& Borkovec, T. D. (1990). Development and validation of the Penn State Worry Questionnaire. Behaviour Research and Therapy, 28, 487-495.

Molina, S., \& Borkovec, T. D. (1994). The Penn State Worry Questionnaire: Psychometric properties and associated characteristics. In G. C. L. Davey \& F. Tallis (Eds.), Worrying: Perspectives on theory, assessment, and treatment (pp. 265-283). Chichester, UK: John Wiley \& Sons.

Moulds, M. L., Kandris, E., \& Williams, A. D. (2007). The impact of rumination on memory for self-referent material. Memory, 15, 814-821.

Nigro, G., \& Neisser, U. (1983). Point of view in personal memories. Cognitive Psychology, 15, 467-482.

O'Keefe, D.J. (2003). Colloquy: Should Familywise Alpha Be Adjusted? Against Familywise Alpha Adjustment. Human Communication Research, 29, 431-447.

Piolino, P., Desgranges, B., Clarys, D., Guillery-Girard, B., Taconnat, L., Isingrini, M., Eustache, F. (2006). Autobiographical memory, autonoetic consciousness, and self-perspective in aging. Psychology and Aging, 21, 510-525.

Power, M. J., \& Dagleish, T. ( 2008). Cognition and emotion: From order to disorder (2nd ed.). Hove, U.K.: Taylor Francis.

Rasmussen, A.S., \& Berntsen, D. (2009). Emotional valence and the functions of autobiographical memories: Positive and negative memories serve different functions. Memory \& Cognition, 37, 477-492. 
Rice, H. J. (2010). Seeing where we're at: A review of visual perspective and memory retrieval. In J. H. Mace (Ed.), The act of remembering: Toward an understanding of how we recall the past. Wiley-Blackwell.

Rice, H. J., \& Rubin, D. C. (2009). I can see it both ways: First- and third-person visual perspectives at retrieval. Consciousness and Cognition, 18, 877-890.

Rice, H. J., \& Rubin, D. C. (2011). Remembering from any angle: The flexibility of visual perspective during retrieval. Consciousness and Cognition, 20, 568-577.

Robinaugh, D. J., \& McNally, R. J. (2010). Autobiographical memory for shame or guilt provoking events: Association with psychological symptoms. Behaviour Research and Therapy, 48, 646-652.

Robinson, J. A., \& Swanson, K. L. (1993). Field and observer modes of remembering. Memory, 1, 169-184.

Roemer, L., Salters, K., Raffa, S. D., \& Orsillo, S. M. (2005). Fear and avoidance of internal experiences in GAD: Preliminary tests of a conceptual model. Cognitive Therapy and Research, 29, 71-88.

Rubin, D. C., Burt, C. D. B., \& Fifield, S. J. (2003). Experimental manipulations of the phenomenology of memory. Memory and Cognition, 31, 877-886.

Rubin, D. C., Schrauf, R. W., \& Greenberg, D. L. (2003). Belief and recollection of autobiographical memories. Memory and Cognition, 31, 887-901.

Salters-Pedneault, K., Tull, M. T., \& Roemer, L. (2004). The role of avoidance of emotional material in the anxiety disorders. Applied and Preventive Psychology, 11, 95-114. 
This article may not exactly replicate the final version published in the APA journal. It is not the copy of record. A definitive version was subsequently published in Psychology of Consciousness: Theory, Research, and Practice, 1, $387-$ 406. Link to the article: http//dx.doi.org/10.1037/cns0000029 (C) 2014 APA

Scheier, M. F., \& Carver, C. S. (1985). The self-consciousness scale: A revised version for use with general populations. Journal of Applied Social Psychology, 15, 687-699.

Spielberger, C. D., Gorsuch, R. L., Lushene, R. E., Vagg, P. R., \& Jacobs, A. G. (1977). State Trait Anxiety Inventory, Palo Alto, CA: Consulting Psychology Press, Inc.

Talarico, J. M., LaBar, K., \& Rubin, D. C. (2004). Emotional intensity predicts autobiographical memory experience. Memory and Cognition, 32, 1118-1132.

Talarico, J. M. \& Rubin, D. C. (2003). Confidence, not consistency, characterizes flashbulb memories. Psychological Science, 14, 455-461.

Terry, W. S., \& Horton, G. P. (2007-2008). A comparison of self-rated emotion in field and observer perspective memories. Imagination, Cognition and Personality, 27, 27-35.

Thomsen, D. K. (2006). The association between rumination and negative affect: A review. Cognition \& Emotion, 20, 1216-1235.

Trapnell, P. D., \& Campbell, J. D. (1999). Private self-consciousness and the five factor model of personality: Distinguishing rumination from reflection. Journal of Personality and Social Psychology, 76, 284-304.

Watkins, E. R. (2008). Constructive and unconstructive repetitive thought. Psychological Bulletin, 134, 163-206.

Watkins, E., Moulds, M., \& Mackintosh B. (2005). Comparison between rumination and worry in a non-clinical population. Behaviour Research and Therapy, 43, 1577-1585.

Wells, A., Clark, D.M., \& Ahmad, S. (1998). How do I look with my minds eye: perspective taking in social phobic imagery. Behaviour Research and Therapy, 36, 631-634. 
This article may not exactly replicate the final version published in the APA journal. It is not the copy of record. A definitive version was subsequently published in Psychology of Consciousness: Theory, Research, and Practice, 1, $387-$ 406. Link to the article: http//dx.doi.org/10.1037/cns0000029 (c) 2014 APA

Wells, A., \& Papageorgiou, C. (1999). The observer perspective: biased imagery in social phobia, agoraphobia, and blood/injury phobia. Behaviour Research and Therapy, 37, 653-658.

Weathers, F. W., Litz, B. T., Huska, J. A., \& Keane, T. M. (1994). The PTSD checklist (PCL). Unpublished scale available from the National Center for PTSD, Washington, DC.

Williams, A. D., \& Moulds, M. L. (2007). Cognitive avoidance of intrusive memories: Recall vantage perspective and associations with depression. Behaviour Research and Therapy, 45, $1141-1153$.

Williams, A. D., \& Moulds, M. L. (2008). Manipulating recall vantage perspective of intrusive memories in dysphoria. Memory, 16, 742-750.

Wilson, A., \& Ross, M. (2003). The identity function of autobiographical memory: Time is on our side. Memory, 11, 137-149.

Wong, Q. J. J., \& Moulds, M. L. (2012). Processing mode during repetitive thinking in socially anxious individuals: Evidence for a maladaptive experiential mode. Journal of Behavior Therapy and Experimental Psychiatry, 43, 1064-1073. 
Table 1

Questions included in the questionnaire for each future projection in Study 1

1. [Specificity] Does this future projection refer to a specific situation in your future? (yes/no).

2. [Vividness] When the future projection came to mind, I could see and/or hear in my mind what happened. ( $1=$ "not at all"; 7 = "to a great extent").

3. [Perspective] When the future projection came to mind, it was as if I predominantly saw what happened from the perspective of: ( 1 = "my own eyes"; 7 = "an observer's eyes").

4. [Valence] Is the future projection about a positive or negative event? (-3 = "very negative"; $3=$ "very positive").

5. [Intensity] Is the future projection about an emotionally intense event? (1 = "without intensity"; 7 $=$ "very intense").

6. [Life story] Would the imagined event become central to your life story? $(1=$ "not central to life story"; 7 = "very central to life story").

7. [Importance] Would the imagined event become important for your life? $(1=$ "not at all"; $7=$ "to a great extent").

8. [Identity] Would the imagined event become central to your personal identity? ( $1=$ "not central for identity"; 7 = "very central for identity").

9. [Reference point] Would the imagined event become a reference point, for the way you understand yourself and the world? ( 1 = "not at all"; 7 = "to a great extent").

10. [Consequences] Do you often think about, which consequences this event would have for your extended future? 1 = "not at all"; 7 = "to a great extent").

11. [Age of event] How old are you, when the imagined event takes place? (Age in years).

Note. Labels in square brackets indicate variable names in the analyses. Questions for autobiographical memories were the same, except for temporal reference. 
This article may not exactly replicate the final version published in the APA journal. It is not the copy of record. A definitive version was subsequently published in Psychology of Consciousness: Theory, Research, and Practice, 1, $387-$ 406. Link to the article: http//dx.doi.org/10.1037/cns0000029 (C) 2014 APA

Table 2

Participant characteristics in Study 1

\begin{tabular}{llccccc} 
& High worriers & Low worriers & & & \\
& \multicolumn{1}{c}{$M(S D)$} & $M(S D)$ & $t / x^{2}$ & $\mathrm{df}$ & $p$ \\
\hline Age & $22.79(1.89)$ & $25.00(6.32)$ & 1.27 & 30 & .22 \\
Females:Males & $12: 2$ & $11: 7$ & & & $.24^{\dagger}$ \\
Pre-PSWQ & $68.36(4.25)$ & $30.61(5.05)$ & 22.42 & 30 & $<.001$ \\
Post-PSWQ & $69.41(4.40)$ & $29.89(4.56)$ & 24.68 & 30 & $<.001$ \\
\hline
\end{tabular}

Note. Total number of participants was 14 in the high worrier group and 18 in the low worrier group.

†Fisher's exact test was used to assess differences in the distribution of number of males and females in the two groups, as assumptions of the Chi square test were broken. 
Table 3

Means and standard deviations for individual differences measures used in Study 2

\begin{tabular}{lcccc} 
& $N$ & $M$ & $S D$ & Range \\
\hline BDI-II & 115 & 8.49 & 7.93 & $0-43$ \\
SIAS & 115 & 19.34 & 12.27 & $1-64$ \\
ERQ-Reappraisal & 115 & 28.50 & 6.34 & $10-42$ \\
ERQ-Suppression & 115 & 10.43 & 4.85 & $4-25$ \\
PSWQ & 115 & 48.42 & 12.58 & $26-80$ \\
RRQ-Rumination & 115 & 39.67 & 9.46 & $19-65$ \\
RRQ-Reflection & 115 & 44.57 & 8.28 & $19-60$ \\
STAI-state & 113 & 36.85 & 11.43 & $20-69$ \\
STAI-trait & 114 & 38.72 & 12.02 & $21-72$ \\
PCL & 115 & 28.79 & 10.81 & $17-66$
\end{tabular}

Note. BDI-II $=$ Beck Depression Inventory $2^{\text {nd }}$ Edition; SIAS = Social Interaction Anxiety Scale; ERQ = Emotion Regulation Questionnaire; PSWQ = Penn State Worry Questionnaire; RRQ = Rumination-Reflection Questionnaire; STAI = State-Trait Anxiety Inventory; PCL = PTSD Check List. 
This article may not exactly replicate the final version published in the APA journal. It is not the copy of record. A definitive version was subsequently published in Psychology of Consciousness: Theory, Research, and Practice, 1, 387-406. Link to the article: http//dx.doi.org/10.1037/cns0000029 @ 2014 APA

Table 4

Correlations between observer perspective and individual differences in Study 2

\begin{tabular}{|c|c|c|c|c|c|}
\hline $\begin{array}{l}\text { Individual differences } \\
\text { measures }\end{array}$ & $\begin{array}{l}\text { Perspective: } \\
\text { pride }\end{array}$ & $\begin{array}{l}\text { Perspective: } \\
\text { shame }\end{array}$ & $\begin{array}{l}\text { Perspective: } \\
\text { Admiration }\end{array}$ & $\begin{array}{l}\text { Perspective: } \\
\text { Contempt }\end{array}$ & $\begin{array}{l}\text { Perspective: } \\
\text { Mean across four } \\
\text { events }\end{array}$ \\
\hline BDI-II & .05 & -.05 & $.25^{\mathrm{a}}$ & .06 & .14 \\
\hline SIAS & .13 & .13 & $.28 *$ & .14 & $.26 *$ \\
\hline ERQ-Reappraisal & -.01 & -.11 & $-.23^{\mathrm{a}}$ & .02 & -.10 \\
\hline ERQ-Suppression & -.05 & -.03 & .15 & .07 & .06 \\
\hline PSWQ & $.21^{\mathrm{a}}$ & .12 & $.21^{\mathrm{a}}$ & .07 & $.22^{\mathrm{a}}$ \\
\hline RRQ-Rumination & .13 & .17 & $.25^{\mathrm{a}}$ & .21 & $.26 *$ \\
\hline RRQ-Reflection & -.11 & .04 & -.17 & $-.32 *$ & $-.20^{\mathrm{a}}$ \\
\hline STAI-state & .09 & .11 & $.35 * *$ & .04 & $.22^{\mathrm{a}}$ \\
\hline STAI-trait & .15 & .10 & $.32 *$ & .10 & $.25^{*}$ \\
\hline $\mathrm{PCL}$ & .07 & -.05 & $.31 *$ & .11 & $.19^{a}$ \\
\hline
\end{tabular}

Note. $N=97-115$. BDI-II $=$ Beck Depression Inventory $2^{\text {nd }}$ Edition; SIAS = Social Interaction Anxiety Scale; ERQ = Emotion Regulation

Questionnaire; PSWQ = Penn State Worry Questionnaire; RRQ = Rumination-Reflection Questionnaire; STAI = State-Trait Anxiety

Inventory; PCL = PTSD Check List.

${ }^{*} p<.01, * * p<.001,{ }^{\mathrm{a}} p<.05$. 

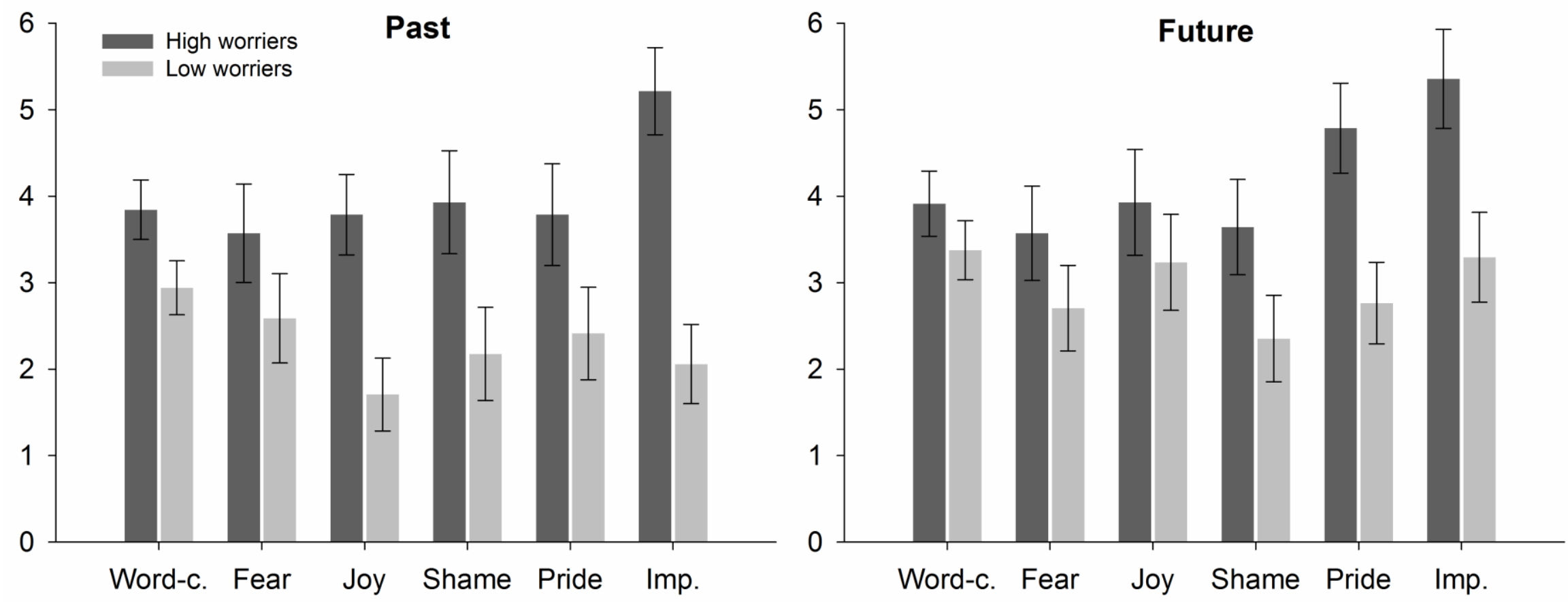

Figure 1. The figure depicts the ratings by high and low worriers of past and future events across different cue categories for perspective in Study 1. Error bars display Standard Error of the Mean for each condition. 
This article may not exactly replicate the final version published in the APA journal. It is not the copy of record. A definitive version was subsequently published in Psychology of Consciousness: Theory, Research, and Practice, 1, 387-406. Link to the article: http//dx.doi.org/10.1037/cns0000029 @ 2014 APA

\section{Appendices, means and standard deviations from Study 1}

Appendices A and B display means and standard deviations for memories (A) and future projections (B) as a function of cue type and worry status.

Appendix A. Means and standard deviations for autobiographical memories high and low worriers in Study 1.

\begin{tabular}{|c|c|c|c|c|c|c|c|c|c|c|c|c|c|c|c|c|c|c|c|c|c|c|c|c|}
\hline & \multicolumn{4}{|c|}{ Word-cue } & \multirow{2}{*}{\multicolumn{2}{|c|}{$\begin{array}{l}\text { Fear } \\
\text { High } \\
\end{array}$}} & \multirow{2}{*}{\multicolumn{2}{|c|}{ Low }} & \multicolumn{4}{|l|}{ Joy } & \multirow{2}{*}{\multicolumn{2}{|c|}{$\begin{array}{l}\text { Shame } \\
\text { High }\end{array}$}} & \multirow{2}{*}{\multicolumn{2}{|c|}{ Low }} & \multicolumn{4}{|l|}{ Pride } & \multirow{2}{*}{\multicolumn{2}{|c|}{$\begin{array}{l}\text { Important } \\
\text { High }\end{array}$}} & \multirow{2}{*}{\multicolumn{2}{|c|}{ Low }} \\
\hline & High & & Low & & & & & & High & & Low & & & & & & High & & Low & & & & & \\
\hline & $M$ & $S D$ & $M$ & $S D$ & $M$ & $S D$ & $M$ & $S D$ & $M$ & $S D$ & $M$ & $S D$ & $M$ & $S D$ & $M$ & $S D$ & $M$ & $S D$ & $M$ & $S D$ & $M$ & $S D$ & $M$ & $S D$ \\
\hline $\begin{array}{l}\text { Specific } \\
\text { (yes/no) }\end{array}$ & .70 & .26 & .78 & .23 & .86 & .36 & .94 & .24 & .79 & .43 & .89 & .32 & .71 & .47 & .94 & .24 & .86 & .36 & .89 & .32 & .86 & .36 & .78 & .43 \\
\hline $\begin{array}{l}\text { See/Hear } \\
\text { (1 to } 7 \text { ) }\end{array}$ & 4.46 & .95 & 4.76 & 1.27 & 5.00 & 2.18 & 4.94 & 1.80 & 5.14 & 1.92 & 5.78 & 1.59 & 4.43 & 1.99 & 4.83 & 1.86 & 5.14 & 1.61 & 5.78 & 1.80 & 4.79 & 2.39 & 5.22 & 2.16 \\
\hline $\begin{array}{l}\text { Perspective } \\
\text { (1 to } 7 \text { ) }\end{array}$ & 3.84 & 1.03 & 2.94 & 1.46 & 3.57 & 2.31 & 2.59 & 1.97 & 3.79 & 1.93 & 1.71 & 1.57 & 3.93 & 2.76 & 2.18 & 1.67 & 3.79 & 2.08 & 2.41 & 2.29 & 5.21 & 1.97 & 2.06 & 1.82 \\
\hline $\begin{array}{l}\text { Reference } p . \\
(1 \text { to } 7)\end{array}$ & 2.34 & .37 & 2.12 & .98 & 3.36 & 2.06 & 3.17 & 1.92 & 3.93 & 2.30 & 3.89 & 2.25 & 3.79 & 2.01 & 3.44 & 2.33 & 3.86 & 2.21 & 4.67 & 2.00 & 5.50 & 1.95 & 5.50 & 1.86 \\
\hline $\begin{array}{l}\text { Consequences } \\
\text { (1 to } 7)\end{array}$ & 1.81 & .51 & 1.66 & .67 & 3.50 & 2.18 & 2.17 & 1.79 & 3.71 & 2.27 & 2.94 & 1.95 & 2.14 & 1.35 & 2.56 & 2.09 & 3.21 & 2.33 & 3.78 & 1.93 & 6.00 & 1.71 & 5.00 & 1.78 \\
\hline $\begin{array}{l}\text { Life story } \\
\text { (1 to } 7)\end{array}$ & 2.54 & .75 & 2.69 & 1.07 & 4.21 & 2.12 & 2.72 & 1.64 & 4.57 & 1.83 & 4.50 & 2.12 & 3.00 & 1.11 & 3.00 & 2.00 & 4.43 & 2.14 & 4.72 & 2.24 & 6.57 & .65 & 6.22 & 1.48 \\
\hline $\begin{array}{l}\text { Importance } \\
\text { (1 to } 7)\end{array}$ & 2.53 & .87 & 2.64 & .84 & 4.14 & 2.21 & 3.00 & 1.53 & 5.14 & 1.75 & 5.33 & 1.61 & 3.43 & 1.40 & 3.56 & 2.23 & 4.57 & 2.14 & 5.33 & 1.68 & 6.57 & .65 & 6.50 & .79 \\
\hline $\begin{array}{l}\text { Identity } \\
\text { (1 to } 7 \text { ) }\end{array}$ & 2.54 & .73 & 2.65 & 1.09 & 3.62 & 2.18 & 2.33 & 1.64 & 4.62 & 2.18 & 4.67 & 1.64 & 3.38 & 1.61 & 3.39 & 2.28 & 4.30 & 2.02 & 4.89 & 1.91 & 6.15 & .90 & 6.33 & 1.08 \\
\hline $\begin{array}{l}\text { Valence } \\
(-3 \text { to } 3)\end{array}$ & .70 & .86 & .52 & 1.24 & -2.14 & 1.41 & -2.17 & .79 & 2.50 & .65 & 2.83 & .38 & -2.14 & 1.66 & -2.33 & .69 & 2.43 & .76 & 2.67 & .59 & 2.07 & .92 & 1.39 & 2.25 \\
\hline $\begin{array}{l}\text { Intensity } \\
\text { ( } 1 \text { to } 7 \text { ) }\end{array}$ & 3.71 & 1.27 & 3.31 & .85 & 6.07 & 1.00 & 5.44 & 1.92 & 5.21 & 2.04 & 5.94 & 1.51 & 5.00 & 2.04 & 5.06 & 1.55 & 5.29 & 2.02 & 5.61 & 1.29 & 5.07 & 1.86 & 6.06 & 1.55 \\
\hline $\begin{array}{l}\text { Distance } \\
\text { (years) }\end{array}$ & 10.28 & 3.69 & 10.15 & 6.94 & 8.09 & 7.18 & 7.73 & 8.18 & 4.91 & 5.39 & 2.33 & 3.06 & 7.91 & 6.14 & 10.33 & 9.92 & 4.82 & 4.64 & 2.20 & 2.40 & 4.73 & 4.78 & 6.40 & 4.50 \\
\hline
\end{tabular}


This article may not exactly replicate the final version published in the APA journal. It is not the copy of record. A definitive version was subsequently published in Psychology of Consciousness: Theory, Research, and Practice, 1, 387-406. Link to the article: http//dx.doi.org/10.1037/cns0000029 @ 2014 APA

Appendix B. Means and standard deviations for future projections for high and low worriers in Study 1.

\begin{tabular}{|c|c|c|c|c|c|c|c|c|c|c|c|c|c|c|c|c|c|c|c|c|c|c|c|c|}
\hline & \multicolumn{4}{|c|}{ Word-cue } & \multirow{2}{*}{\multicolumn{4}{|c|}{$\begin{array}{l}\text { Fear } \\
\text { High }\end{array}$}} & \multicolumn{4}{|l|}{ Joy } & \multirow{2}{*}{\multicolumn{2}{|c|}{$\begin{array}{l}\text { Shame } \\
\text { High }\end{array}$}} & \multirow{2}{*}{\multicolumn{2}{|c|}{ Low }} & \multicolumn{4}{|l|}{ Pride } & \multirow{2}{*}{\multicolumn{2}{|c|}{$\begin{array}{l}\text { Important } \\
\text { High }\end{array}$}} & \multirow{2}{*}{\multicolumn{2}{|c|}{ Low }} \\
\hline & High & & Low & & & & & & High & & Low & & & & & & High & & Low & & & & & \\
\hline & $M$ & $S D$ & $M$ & $S D$ & $M$ & $S D$ & $M$ & $S D$ & $M$ & $S D$ & $M$ & $S D$ & $M$ & $S D$ & $M$ & $S D$ & $M$ & $S D$ & $M$ & $S D$ & $M$ & $S D$ & $M$ & $S D$ \\
\hline $\begin{array}{l}\text { Specific } \\
\text { (yes/no) }\end{array}$ & .51 & .24 & .54 & .29 & .57 & .51 & .44 & .51 & .93 & .27 & .67 & .49 & .50 & .52 & .39 & .50 & .64 & .50 & .61 & .50 & .86 & .36 & .83 & .38 \\
\hline $\begin{array}{l}\text { See/Hear } \\
\text { (1 to } 7 \text { ) }\end{array}$ & 4.27 & 1.32 & 4.44 & 1.26 & 4.21 & 1.93 & 4.00 & 2.38 & 5.14 & 1.61 & 4.67 & 1.50 & 3.43 & 1.74 & 3.00 & 2.11 & 3.64 & 1.78 & 4.00 & 1.81 & 4.86 & 1.88 & 4.56 & 1.65 \\
\hline $\begin{array}{l}\text { Perspective } \\
\text { (1 to } 7)\end{array}$ & 3.91 & 1.37 & 3.38 & 1.44 & 3.57 & 1.95 & 2.71 & 2.11 & 3.93 & 2.62 & 3.24 & 1.99 & 3.64 & 2.21 & 2.35 & 1.93 & 4.79 & 1.93 & 2.76 & 1.95 & 5.36 & 2.41 & 3.29 & 1.90 \\
\hline $\begin{array}{l}\text { Reference } \mathrm{p} . \\
(1 \text { to } 7)\end{array}$ & 2.14 & 1.05 & 2.24 & .74 & 4.71 & 1.27 & 4.50 & 2.09 & 5.21 & 1.93 & 3.56 & 1.92 & 4.43 & 2.38 & 3.94 & 2.07 & 5.07 & 2.20 & 4.56 & 2.04 & 5.93 & 1.59 & 5.06 & 1.89 \\
\hline $\begin{array}{l}\text { Consequences } \\
\text { (1 to } 7)\end{array}$ & 2.26 & 1.10 & 2.19 & .99 & 5.36 & 1.39 & 4.89 & 2.17 & 5.43 & 2.14 & 3.72 & 2.52 & 4.07 & 2.34 & 2.89 & 2.03 & 6.00 & 1.71 & 4.00 & 1.78 & 6.29 & .83 & 5.17 & 1.62 \\
\hline $\begin{array}{l}\text { Life story } \\
\text { (1 to } 7)\end{array}$ & 2.40 & 1.14 & 2.28 & .92 & 5.43 & .94 & 5.78 & 1.31 & 6.43 & 1.60 & 4.44 & 2.06 & 3.93 & 2.23 & 3.61 & 2.28 & 5.93 & 1.21 & 5.89 & 1.64 & 6.71 & .61 & 6.17 & 1.04 \\
\hline $\begin{array}{l}\text { Importance } \\
\text { (1 to } 7)\end{array}$ & 2.56 & 1.30 & 2.83 & 1.02 & 5.07 & 1.44 & 6.06 & 1.21 & 6.43 & 1.60 & 5.33 & 1.64 & 4.29 & 2.52 & 3.94 & 2.10 & 6.50 & .85 & 6.17 & 1.54 & 6.79 & .43 & 6.33 & .69 \\
\hline $\begin{array}{l}\text { Identity } \\
\text { (1 to } 7 \text { ) }\end{array}$ & 2.34 & 1.15 & 2.79 & 1.13 & 3.77 & 1.74 & 4.67 & 1.97 & 5.46 & 1.98 & 4.22 & 2.18 & 4.46 & 1.90 & 3.83 & 1.92 & 5.92 & 1.19 & 5.61 & 1.46 & 6.54 & .78 & 5.33 & 1.53 \\
\hline $\begin{array}{l}\text { Valence } \\
\text { (-3 to } 3)\end{array}$ & 1.20 & .71 & 1.16 & .49 & -1.64 & 1.98 & -2.78 & .54 & 2.86 & .53 & 2.72 & .46 & -2.14 & 1.61 & -2.44 & .70 & 2.64 & .50 & 2.56 & .51 & 2.57 & 1.60 & 2.28 & 1.18 \\
\hline $\begin{array}{l}\text { Intensity } \\
\text { ( } 1 \text { to } 7)\end{array}$ & 2.96 & .97 & 3.26 & 1.06 & 5.93 & 1.38 & 6.39 & .78 & 6.64 & 1.08 & 5.72 & 1.18 & 5.57 & 1.65 & 4.72 & 2.08 & 5.64 & 1.08 & 5.39 & 1.33 & 6.93 & .27 & 5.94 & 1.21 \\
\hline $\begin{array}{l}\text { Distance } \\
\text { (years) }\end{array}$ & 2.31 & 1.42 & 3.23 & 3.22 & 5.45 & 6.50 & 12.67 & 15.89 & 4.82 & 3.52 & 2.80 & 3.53 & 4.27 & 6.07 & 3.20 & 5.51 & 5.64 & 3.61 & 7.70 & 8.08 & 7.27 & 9.60 & 3.90 & 3.13 \\
\hline
\end{tabular}

